\title{
Single-walled Carbon Nanotube Thin Film with High Semiconducting Purity by Aerosol Etching towards Thin Film Transistors
}

Yongping Liao, ${ }^{\dagger,}$ Zhao Zhang, ${ }^{\dagger}$ Qiang Zhang, ${ }^{*,{ }^{\ddagger}}$ Nan Wei, ${ }^{\ddagger}$ Saeed Ahmad, ${ }^{\ddagger}$ Ying Tian,§ Esko I. Kauppinen*,*

${ }^{\dagger}$ School of Textile and Material Engineering, Dalian Polytechnic University, Dalian 116034, China

${ }^{*}$ Department of Applied Physics, Aalto University School of Science, P.O. Box 15100, FI-00076, Aalto, Finland

$\S$ Department of Physics, Dalian Maritime University, Dalian, Liaoning, 116026, China

*Address correspondence to:

qiang.zhang@aalto.fi esko.kauppinen@aalto.fi 


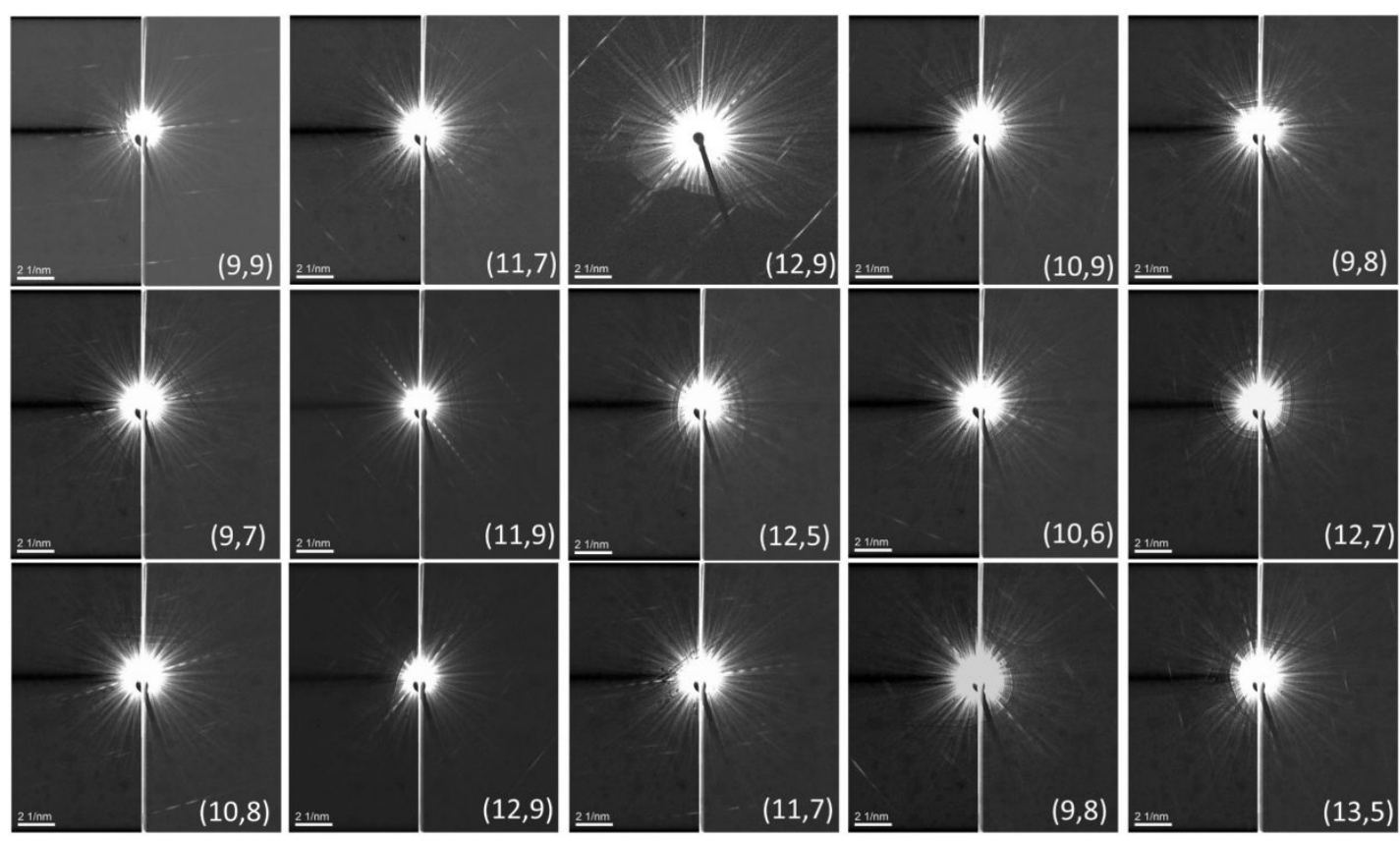

Figure S1. Selected electron diffractions patterns of SWCNTs and their $(n, m)$ from $\mathrm{R} 2$ with $400 \mathrm{sccm}$ of $\mathrm{CO}_{2}$ at $850{ }^{\circ} \mathrm{C}$.

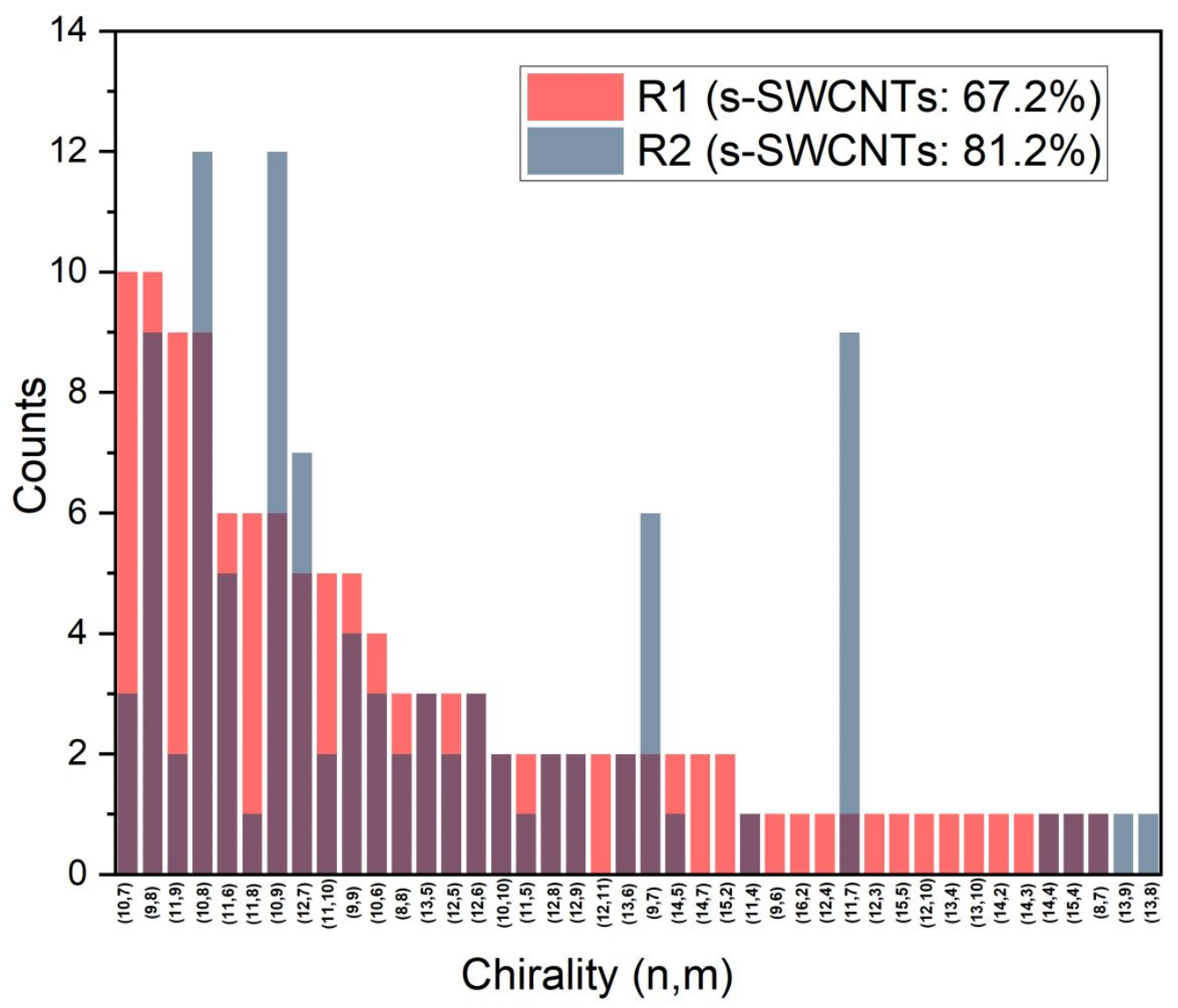

Figure S2. Statistics of $(n, m)$ abundance of SWCNTs from R1 and R2 (400 sccm of $\mathrm{CO}_{2}$ at $850{ }^{\circ} \mathrm{C}$ ). The total counted numbers of tubes from R1 and R2 are 122 and 101 , respectively. 
Table S1. The representative chiralities of metallic tubes and their content calculated from Figure S3.

\begin{tabular}{lcc}
\hline Chirality & Content (R1) & Content (R2) \\
\hline$(10,7)$ & $8.3 \%$ & $3.0 \%$ \\
$(11,8)$ & $4.9 \%$ & $1.0 \%$ \\
$(9,9)$ & $4.1 \%$ & $4.0 \%$ \\
$(8,8)$ & $2.5 \%$ & $2.0 \%$ \\
$(9,6)$ & $0.8 \%$ & 0 \\
$(14,2)$ & $0.8 \%$ & 0 \\
$(12,3)$ & $0.8 \%$ & 0 \\
\hline
\end{tabular}
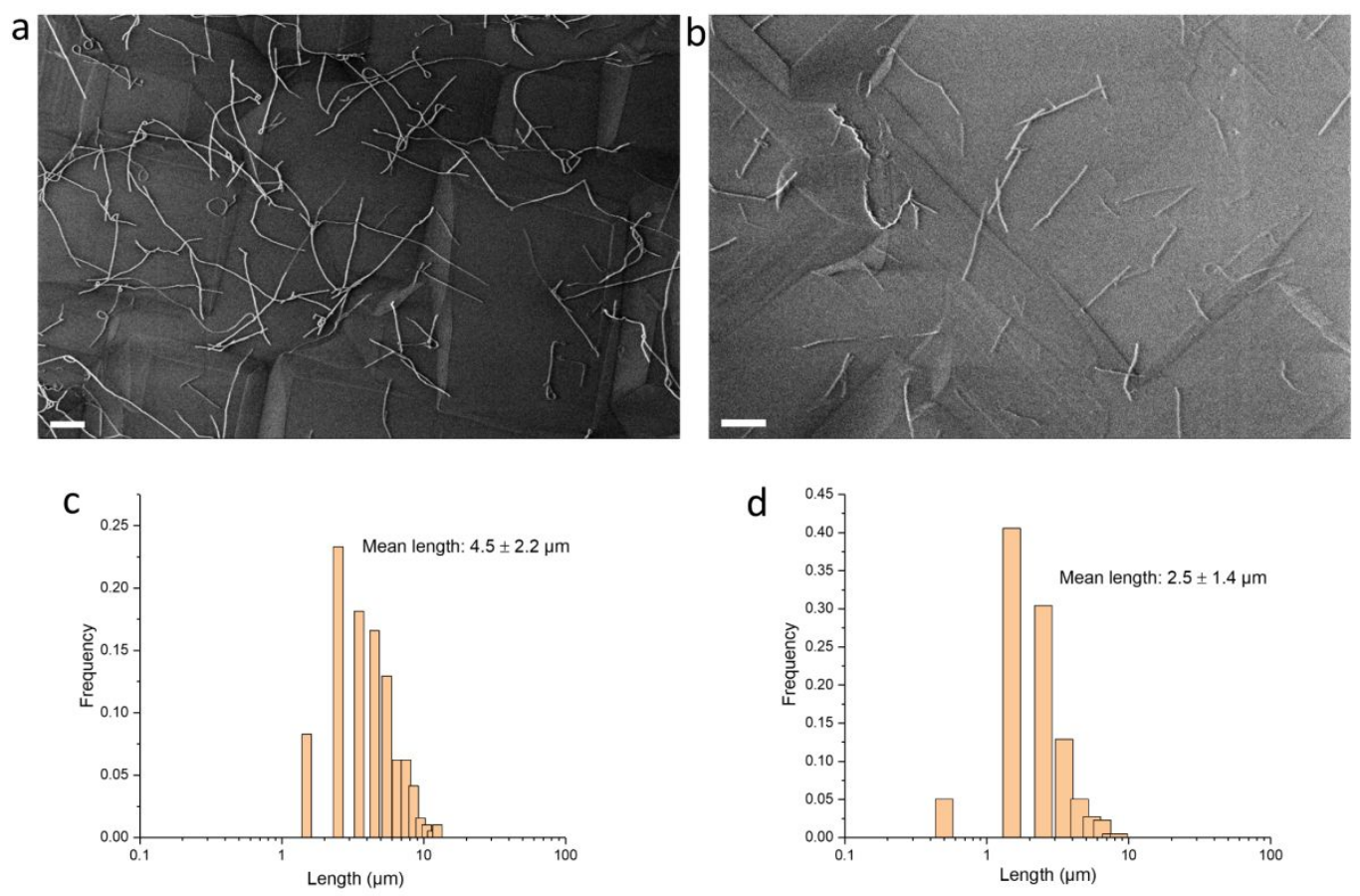

Figure S3. The SEM image and the length distribution of SWCNTs from (a and c) $\mathrm{R} 1$ and (b and d) R2 (400 sccm of $\mathrm{CO}_{2}$ at $\left.850{ }^{\circ} \mathrm{C}\right)$. The scale bars are $2 \mu \mathrm{m}$. 